\title{
Performance of automated ECV maps versus conventionally calculated ECV
}

\author{
Stefania Rosmini ${ }^{*}$, Thomas A Treibel ${ }^{1}$, Amna Abdel-Gadir ${ }^{1}$, Heerajnarain Bulluck${ }^{1}$, Daniel Sado ${ }^{1}$, Charlotte Manisty ${ }^{1}$, \\ Anna S Herrey ${ }^{1}$, Peter Kellman², James Moon ${ }^{1}$
}

From 18th Annual SCMR Scientific Sessions

Nice, France. 4-7 February 2015

\section{Background}

The extracellular volume fraction (ECV) is a surrogate marker for diffuse myocardial fibrosis. ECV is calculated from pre- and post-contrast T1 maps and corrected for hematocrit (Hct). Current workflows are cumbersome, but an automated ECV map tool simplifies this and could promote adoption into routine clinical practice. We assessed the performance of automated ECV maps versus conventional manual ECV quantification in a population of healthy volunteers using a Modified Look-Locker Inversion Recovery (MOLLI) technique.

\section{Methods}

45 healthy volunteers [mean age $43 \pm 12$ years, 21 (47\%) males] underwent $\mathrm{CMR}$ at $1.5 \mathrm{~T}$. with $\mathrm{T} 1$ mapping using
MOLLI. MOLLI T1 maps with motion correction [precontrast $5 \mathrm{~s}(3 \mathrm{~s}) 3 \mathrm{~s}$; post-contrast $4 \mathrm{~s}(1 \mathrm{~s}) 3 \mathrm{~s}(1 \mathrm{~s}) 2 \mathrm{~s}]$ were acquired in the 4 chamber (4Ch) and a mid-ventricular short-axis (SA) pre and 15 minutes post contrast (Dotarem $0.1 \mathrm{mmol} / \mathrm{kg}$ ). A region of interest was manually drawn on the pre-contrast $\mathrm{T} 1 \mathrm{map}$ and a) exported to the post contrast T1 map and b) exported to the ECV map (Figure 1). The ECV map was automatically generated from the source images of the pre and post contrast T1 maps with re-MOCOing and calibrated by blood hematocrit (Kellman JCMR 2012, 14:63). For the manual method, the averages of the ROIs were used in the ECV equation: $\mathrm{ECV}=\left(\Delta\left[1 / \mathrm{T} 1_{\text {myo }}\right] / \Delta\left[1 / \mathrm{T} 1_{\text {blood }}\right]\right)$ * [1-hematocrit]). For the ECV map, the ROI pixel average was the average ECV.

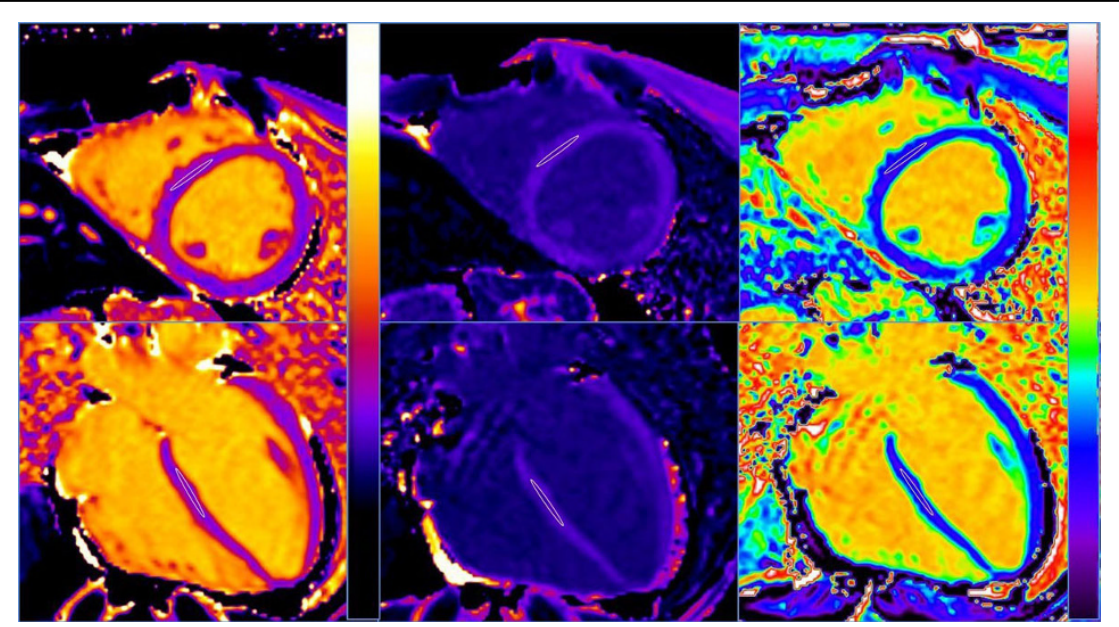

Figure 1 Native T1 maps (left column), post contrast T1 maps (middle column) and ECV maps (right column) in a short axis (top row) and 4 chamber (bottom row).

The Heart Hospital Imaging Centre, University College London Hospitals,

London, UK

Full list of author information is available at the end of the article 

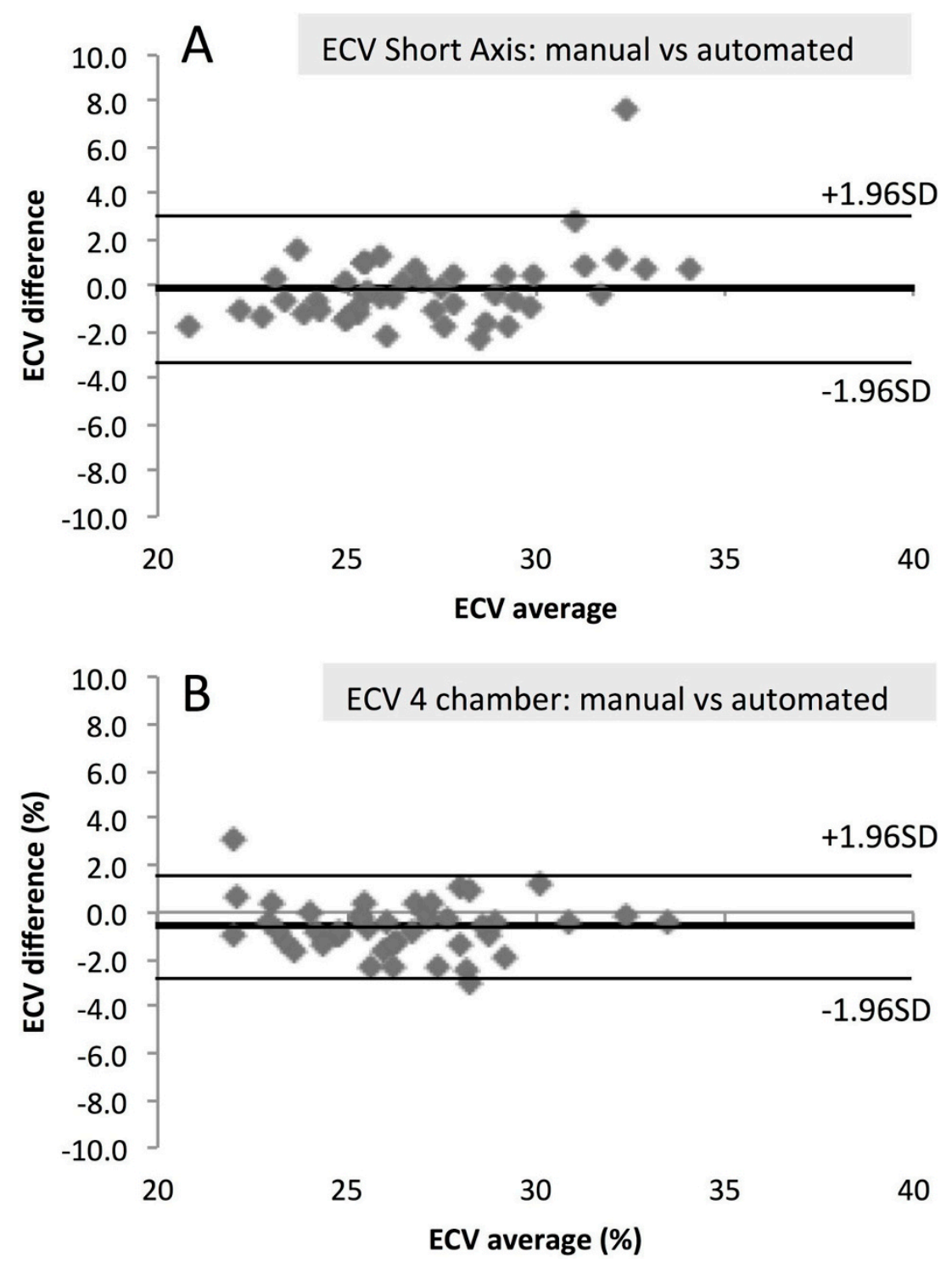

Figure 2 Bland-Altman Plots of ECV by automated vs manual method in the short axis (A) and 4 chamber (B).

\section{Results}

ECV maps resulted in a higher ECV in the SA than in the 4 Ch $(27.0 \pm 3.5 \%$ vs $25.9 \pm 2.8 \% ; p=0.007)$; this difference did not reach significance in the manual technique (27.1 $\pm 2.8 \%$ vs $26.6 \pm 2.9 \%$; $\mathrm{p}=0.075$ ).

In the $4 \mathrm{Ch}, \mathrm{ECV}$ was higher using the manual rather than the automatic technique $(26.6 \pm 2.9 \%$ vs $25.9 \pm 2.8 \%$, $p<0.001)$. There was excellent correlation between both techniques $(\mathrm{R}=0.92 ; \mathrm{p}<0.001)$. Bland Altman analysis revealed minimal bias and no significant variability (bias $-0.6 \%, 95 \% \mathrm{CI} \pm 2.2 \%$ ) (Fig. 2B).

In the mid-SA, ECV was not significantly different between manual and automatic technique $(27.1 \pm 2.8 \%$ vs $27.0 \pm 3.5 \% ; p=0.546)$ with excellent correlation $(\mathrm{R}=0.89$; $\mathrm{p}<0.001)$. Bland Altman analysis revealed no bias or variability (bias $-0.15,95 \% \mathrm{CI} \pm 3.2 \%$ ) (Fig. $2 \mathrm{~A}$ ).

\section{Conclusions}

Automated ECV maps significantly improve workflow and show good agreement with the manual method. Application in the short axis showed no difference to the manual approach, but result in slightly higher ECV with more variability than in the 4 chamber. Further validation in health and disease with wider ECV ranges is needed.

\section{Funding}

TAT and MF are supported by doctoral research fellowships by the National Institute of Health Research and British Heart Foundation, respectively. 


\section{Authors' details}

${ }^{1}$ The Heart Hospital Imaging Centre, University College London Hospitals,

London, UK. ${ }^{2}$ National Heart, Lung and Blood Institute, Bethesda, MD, USA.

Published: 3 February 2015

doi:10.1186/1532-429X-17-S1-P56

Cite this article as: Rosmini et al:: Performance of automated ECV maps versus conventionally calculated ECV. Journal of Cardiovascular Magnetic Resonance 2015 17(Suppl 1):P56.

Submit your next manuscript to BioMed Central and take full advantage of:

- Convenient online submission

- Thorough peer review

- No space constraints or color figure charges

- Immediate publication on acceptance

- Inclusion in PubMed, CAS, Scopus and Google Scholar

- Research which is freely available for redistribution

Submit your manuscript at www.biomedcentral.com/submit 